\title{
The Birth of an Adenoid Cystic Carcinoma
}

\author{
Nicola Fusco, MD ${ }^{1,2}$, Elena Guerini-Rocco, MD ${ }^{1,2}$, Anne M. Schultheis, MD ${ }^{1}$, Sunil S. Badve, MD, \\ FRCPath ${ }^{3}$, Jorge S. Reis-Filho, MD, PhD, FRCPath ${ }^{1}$, and Britta Weigelt, $\mathrm{PhD}^{1}$ \\ 1 Memorial Sloan Kettering Cancer Center, New York, NY, USA \\ 2 University of Milan, Milan, Italy \\ 3 Indiana University School of Medicine, Indianapolis, IN, USA
}

Adenoid cystic carcinoma is a rare malignancy of exocrine glands defined by the presence of a dual population of cells (epithelial and myoepithelial cells) organized in varying combinations of cribriform, tubular, and solid patterns.1,2 This neoplasm most frequently originates in the salivary glands; however, it can also occur in other anatomical sites, including the breast.1,3 More than $90 \%$ of adenoid cystic carcinomas of the breast harbor the recurrent translocation $\mathrm{t}(6 ; 9)$, resulting in the MYB-NFIB fusion gene, which leads to MYB overexpression.4 Adenoid cystic carcinoma in situ has been described in the breast; however, its identifica-tion is not trivial.3 Here, we illustrate an in situ adenoid cystic carcinoma partially involving a mammary duct in a 68-year-old woman with primary adenoid cystic carci-noma of the right breast. The double population of cells composing this intraductal lesion can be appreciated by its immunohistochemical profile (Figure 1). Given that the neoplastic cells of the in situ lesion already express MYB, our findings are consistent with the notion that MYB overexpression is an early event in the tumorigen-esis of adenoid cystic carcinomas.4,5

This is the author's manuscript of the article published in final edited form as:

Fusco, N., Guerini-Rocco, E., Schultheis, A. M., Badve, S. S., Reis-Filho, J. S., \& Weigelt, B. (2015). The birth of an adenoid cystic carcinoma. International Journal of Surgical Pathology, 23(1), 26-27. http://doi.org/10.1177/1066896914548795 


\section{References}

1. Barnes L, Eveson J, Reichart P, Sidransky D. World Health Organization Classification of Tumours. Pathology and Genetics of Head and Neck Tumours. 3rd ed. Lyon, France: IARC Press; 2005.

2. Marchio C, Weigelt B, Reis-Filho JS. Adenoid cystic carci-nomas of the breast and salivary glands (or “The strange case of Dr Jekyll and Mr Hyde” of exocrine gland carcinomas). J Clin Pathol. 2010;63:220-228.

3. Hoda SA, Brogi E, Koerner F, Rosen PP. Rosen’s Breast Pathology. 4th ed. Philadelphia, PA: Wolters Kluwer Health; 2014.

4. Wetterskog D, Lopez-Garcia MA, Lambros MB, et al. Adenoid cystic carcinomas constitute a genomically distinct subgroup of triple-negative and basal-like breast cancers. J Pathol. 2012;226:84-96.

5. Costa AF, Altemani A, Garcia-Inclan C, et al. Analysis of MYB oncogene in transformed adenoid cystic carcinomas reveals distinct pathways of tumor progression. Lab Invest. 2014;94:692-702. 
Figure 1.

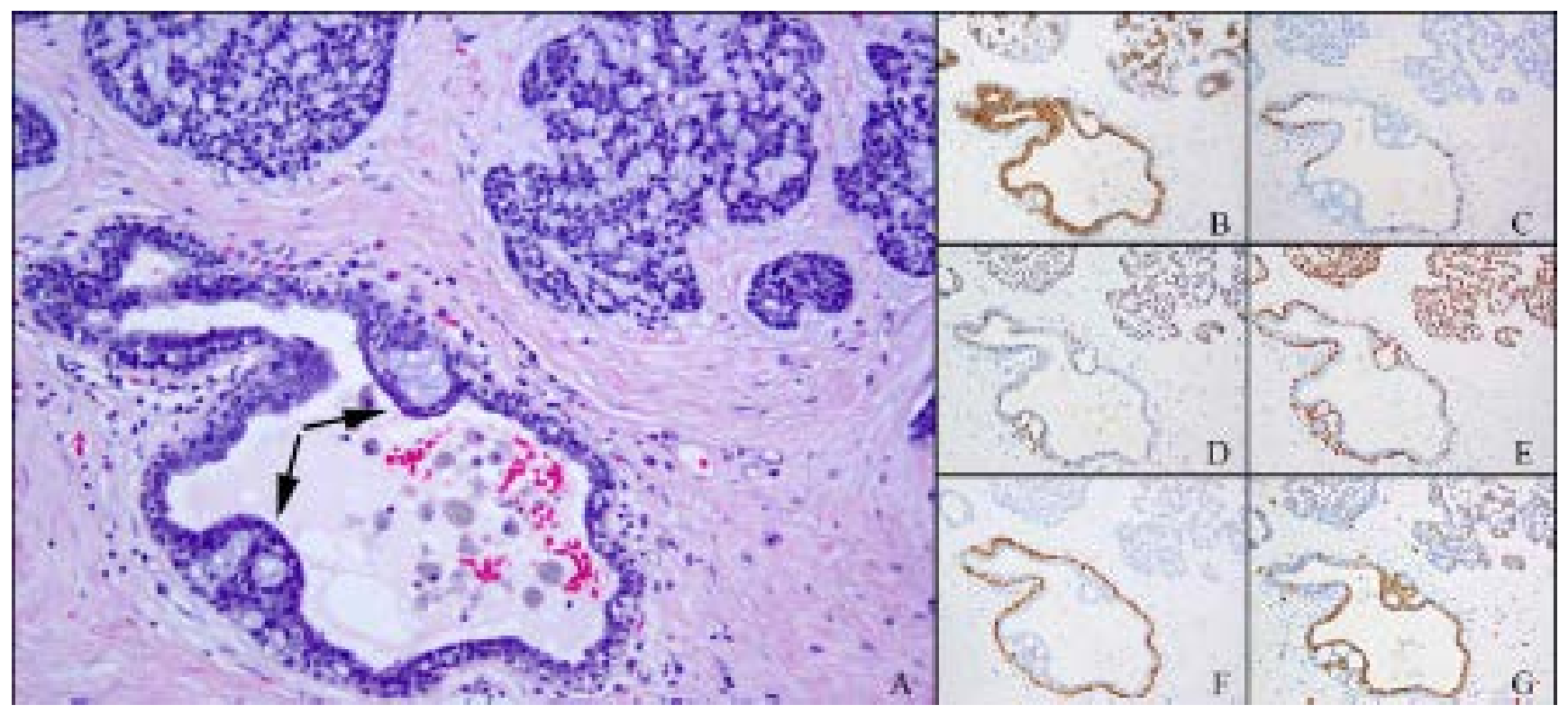

Figure 1. In situ adenoid cystic carcinoma (arrows) partially involving a duct (A; hematoxylin and eosin) associated with a primary adenoid cystic carcinoma of the breast (upper part of the micrograph). The partially involved duct contained nonneoplastic CK7-positive luminal cells (B), some of which were estrogen receptor-positive (C), and an in situ adenoid cystic carcinoma displaying MYB (D) and p63 (E) co-expression. The intact layer of myoepithelial cells surrounding the duct was highlighted by expression of p63 (E) and calponin (F). While p63 was also expressed in the in situ and invasive adenoid cystic carcinoma cells (E), c-KIT expression was observed in both the normal breast luminal epithelial cells and cells surrounding the pseudo-cystic structures of the in situ and invasive adenoid cystic carcinoma (G). 